\section{Histologic studies of the intraocular toxicity of imatinib mesylate in rabbits}

\begin{abstract}
Purpose To evaluate histologic signs of toxicity of the protein tyrosine kinase inhibitor, imatinib mesylate, in rabbit eyes. Methods Twenty Dutch-belted rabbits underwent intravitreal injections of $0.1 \mathrm{ml}$ solutions of imatinib mesylate. Ten rabbits were killed and enucleated 1 week after injection of imatinib mesylate (1.65 mg (four eyes), $165 \mu \mathrm{g}$ (four eyes), and $16.5 \mu \mathrm{g}$ (two eyes)). Ten rabbits injected with imatinib mesylate (165 $\mu$ g (five eyes) and $825 \mu \mathrm{g}$ (five eyes)) were enucleated 1 month later. Eyes were fixed in $\mathbf{1 0 \%}$ formalin and stained with haematoxylin and eosin for microscopic examination.
\end{abstract}

Results All four eyes injected with $1.65 \mathrm{mg}$ of imatinib mesylate and enucleated at 1 week demonstrated ocular toxicity. All four eyes injected with $165 \mu \mathrm{g}$ and enucleated at 1 week showed no ocular toxicity. One of the two eyes injected with $16.5 \mu \mathrm{g}$ and enucleated at 1 week revealed focal areas of subretinal fluid and retinal undulations, suggestive of retinal oedema. None of the 10 eyes injected with imatinib mesylate at either the 165 or $825 \mu \mathrm{g}$ dose and enucleated at 1 month showed ocular toxicity.

Conclusions Imatinib mesylate at $1.65 \mathrm{mg}$ caused extensive retinal toxicity in rabbit eyes. In contrast, lower doses did not appear to cause toxicity, but may be associated with retinal oedema.

Eye (2008) 22, 712-714; doi:10.1038/sj.eye.6703092; published online 1 February 2008

Keywords: drug toxicity; protein tyrosine kinases; antineoplastic agents; rabbits; injections

\section{Introduction}

Intraocular tumours have traditionally been treated with either systemic treatments
AS Kitzmann', KH Baratz', BG Mohney', JS Pulido', JD Cameron ${ }^{1}$, ES Lee ${ }^{1}$ and EB Leof ${ }^{2}$ (chemotherapy or external beam radiation), surgery (enucleation), or local treatments (ie, laser photocoagulation, brachytherapy, transpupillary thermotherapy). Recently, the use of intraocular chemotherapy, specifically, methotrexate, has shown benefit in treatment of intraocular non-Hodgkin's lymphoma. ${ }^{1}$ The advantages of intraocular chemotherapeutic agents include decreased systemic side effects and higher drug concentrations delivered to the tumour.

Imatinib mesylate (Novartis, Gleevec) is a protein tyrosine kinase inhibitor. Tyrosine kinases are enzymes that play an important role in growth factor signalling. Activated tyrosine kinsases can cause increases in tumour cell growth, induce antiapoptotic effects, and promote angiogenesis and metastasis. ${ }^{2}$ Abnormal activation of tyrosine kinases is frequent during the development and progression of human cancers, such as chronic myeloid leukaemia, gastrointestinal stromal tumours, and non-small-cell lung cancer.

The intraocular toxicity of many systemic antineoplastic agents, including imatinib mesylate, is unknown, and this agent may be a promising new therapy for intraocular tumours. Therefore, the purpose of this study was to investigate the histologic toxicity of imatinib mesylate in rabbit eyes.

\section{Materials and methods}

Approval was obtained from the Mayo Clinic Institutional Animal Care and Use Committee. Twenty-two $1.5 \mathrm{~kg}$ Dutch-belted male rabbits (Harlan Laboratories, Indianapolis, IN, USA) were anaesthetized with $35 \mathrm{mg} / \mathrm{kg}$ of intramuscular ketamine hydrochloride (Fort Dodge Inc., Fort Dodge, IN, USA), $5 \mathrm{mg} / \mathrm{kg}$ of intramuscular xylazine hydrochloride (Phoenix Scientific Inc., St Joseph, MO, USA), and 1\% proparacaine hydrochloride ophthalmic drops 
(Allergan America, Hormigueros, Puerto Rico). Using a 30-gauge needle, 20 rabbits had $0.1 \mathrm{ml}$ of imatinib mesylate injected intravitreally into the right eye at the following concentrations: $1.65 \mathrm{mg} / 0.1 \mathrm{ml}$ (four eyes), $825 \mu \mathrm{g} / 0.1 \mathrm{ml}$ (five eyes), $165 \mu \mathrm{g} / 0.1 \mathrm{ml}$ (nine eyes), $16.5 \mu \mathrm{g} / 0.1 \mathrm{ml}$ (two eyes). For a control group, two rabbits were injected with $0.1 \mathrm{ml}$ of balanced salt solution (Alcon) in the right eye and killed at 1 week. The noninjected left eyes also served as a control group.

The initial dose of imatinib mesylate was $1.65 \mathrm{mg}$. The rationale for this dose was based on a study that showed that imatinib mesylate inhibits vascular endothelial growth factor (VEGF) expression in vitro in small-cell lung cancer cells. ${ }^{3}$ Imatinib mesylate inhibited VEGF expression at $5 \mu \mathrm{mol} / \mathrm{l}$, which is about $3 \mu \mathrm{g} / \mathrm{ml}$. We therefore wanted a higher dose (ie, $1.65 \mathrm{mg} / 0.1 \mathrm{ml}$ ). Subsequent doses were then based on the histopathologic findings of eyes injected with this dose.

Of the rabbits injected with imatinib mesylate, 10 rabbits were killed at 1 week: $1.65 \mathrm{mg}$ (four eyes), $165 \mu \mathrm{g}$ (four eyes), and $16.5 \mu \mathrm{g}$ (two eyes). At 1 month, 10 rabbits injected with imatinib mesylate were killed $(825 \mu \mathrm{g}$ (five eyes) and $165 \mu \mathrm{g}$ (five eyes)).

The animals were killed with intravenous pentobarbital (Beuthanasia-D Special; Schering-Plough, Kenilworth, NJ, USA). Both eyes were enucleated, fixed with $2 \%$ paraformaldehyde, paraffin-embedded, sectioned, and stained with haematoxylin and eosin. The sections were evaluated by light microscopy by a pathologist masked to drug concentrations. Statistical analysis could not be performed due to the small numbers of animals in each group.

We certify that all applicable institutional and governmental regulations concerning the ethical use of animals were followed during this research.

\section{Results}

All four eyes injected with $1.65 \mathrm{mg}$ of imatinib mesylate and enucleated at 1 week had full-thickness retinal necrosis and chronic nongranulomatous inflammation in the posterior retina, posterior subcapsular cataract, and chronic nongranulomatous vitritis (Figure 1, Table 1). All four eyes injected with $165 \mu \mathrm{g}$ and enucleated at 1 week showed no ocular toxicity. One of the two eyes injected with $16.5 \mu \mathrm{g}$ and enucleated at 1 week revealed focal areas of subretinal fluid and retinal undulations, suggestive of retinal oedema (Figure 2).

Of the 10 eyes injected with imatinib mesylate and enucleated at 1 month, one eye ( $825 \mu \mathrm{g}$ dose) had focal chorioretinal adhesion with intraretinal gliosis in the absence of retinal inflammation or vitritis. One eye (165 $\mu \mathrm{g}$ dose) had rupture of the posterior lens capsule. Findings in these two eyes were suggestive of injection-related mechanical trauma rather than toxicity.
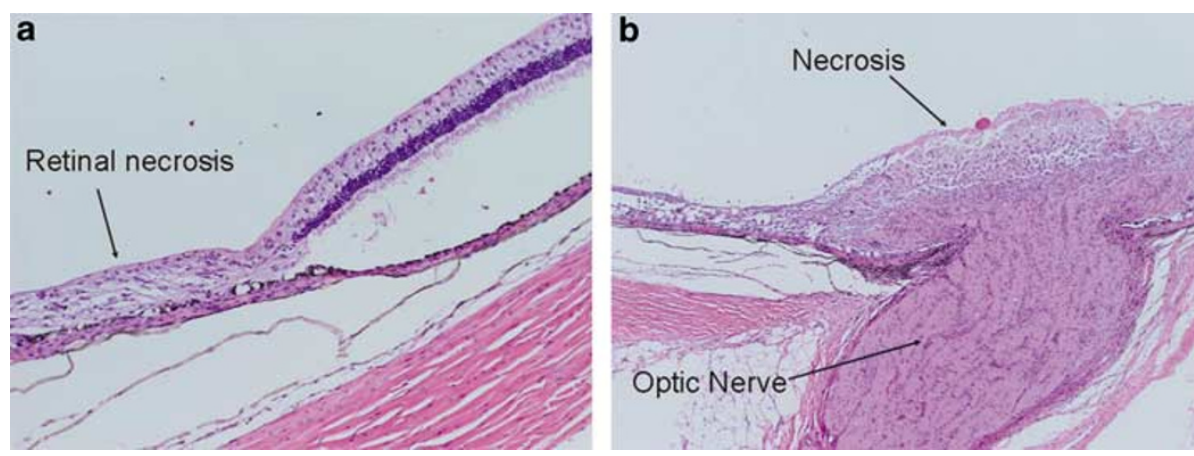

Figure 1 Photomicrographs of a rabbit eye injected with $1.65 \mathrm{mg}$ of imatinib mesylate and enucleated after 1 week. There is fullthickness retinal necrosis (a) and optic nerve necrosis (b) (haematoxylin-eosin stain, original magnification $\times 40$ ).

Table 1 Histologic results of 20 rabbit eyes injected with imatinib mesylate

\begin{tabular}{|c|c|c|c|c|}
\hline Drug & Dose & $\begin{array}{l}\text { No. of } \\
\text { eyes }\end{array}$ & Enucleation & Histopathologic results \\
\hline Imatinib & $1.65 \mathrm{mg}$ & 4 & 1 week & $\begin{array}{l}\text { All four eyes had full-thickness retinal necrosis, posterior pole inflammation, } \\
\text { vitiritis, and posterior subcapsular cataract (Figure 1). }\end{array}$ \\
\hline Imatinib & $825 \mu \mathrm{g}$ & 5 & 1 month & $\begin{array}{l}\text { One eye had a focal chorioretinal adhesion with intraretinal gliosis in the absence } \\
\text { of retinal inflammation or vitiris, suggestive of injection-related trauma. }\end{array}$ \\
\hline Imatinib & $165 \mu \mathrm{g}$ & 4 & 1 week & No ocular toxicity \\
\hline Imatinib & $165 \mu \mathrm{g}$ & 5 & 1 month & One eye had rupture of the posterior lens capsule, suggestive of injection-related trauma. \\
\hline Imatinib & $16.5 \mu \mathrm{g}$ & 2 & 1 week & $\begin{array}{l}\text { One eye showed focal areas of subretinal fluid and retinal undulations suggestive } \\
\text { of retinal edema (Figure 2). }\end{array}$ \\
\hline
\end{tabular}




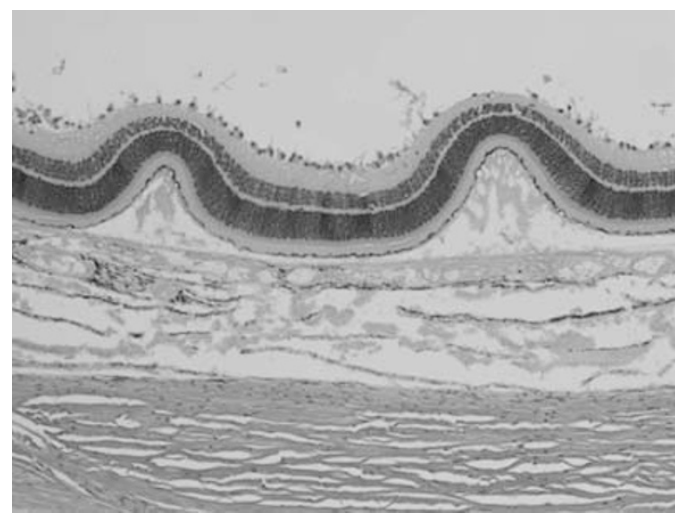

Figure 2 Photomicrograph of a rabbit eye injected with $16.5 \mu \mathrm{g}$ of imatinib mesylate and enucleated after 1 week. There are focal areas of subretinal fluid and retinal undulations, suggestive of retinal oedema (haematoxylin-eosin stain, original magnification $\times 100)$

No eyes at any dose had histologic signs of toxicity involving any other intraocular tissue.

No abnormalities were noted in any of the control eyes that received no intraocular injection (although one control eye had the posterior pole and optic nerve amputated at the time of enucleation). No abnormalities were noted in the two eyes injected with balanced salt solution.

\section{Discussion}

With the advent of antivascular endothelial growth factors, such as bevacizumab and ranibizumab, the treatment of a variety of retinal diseases, from macular degeneration to diabetic retinopathy and retinal vascular occlusions, is rapidly changing to one based on intravitreal medications, rather than other forms of treatment, such as laser photocoagulation. Similarly, for intraocular tumours, the recent use of intravitreal methotrexate for intraocular lymphoma has initiated the investigation of other agents that could be given intravitreally. ${ }^{1}$ The obvious advantage to intravitreal administration is the higher drug concentration to the intraocular tumour or intraocular pathology with lower systemic side effects. However, the intraocular toxicity of many neoplastic agents is currently unknown. Therefore, the purpose of this study was to investigate the intraocular toxicity of imatinib mesylate.

With systemic use, imatinib occasionally causes ocular side effects such as periorbital oedema and epiphora, but intraocular toxicity has not been reported, to our knowledge. ${ }^{4}$ However, progression of intraocular disease in otherwise responsive leukaemia may occur with systemic therapy. ${ }^{5}$

In this study, we injected various concentrations (from $1.65 \mathrm{mg}$ to $16.5 \mu \mathrm{g}$ ) of imatinib mesylate intravitreally into rabbit eyes and found that at higher doses, full-thickness retinal necrosis developed in all eyes. However, at lower doses, except for one eye at the $16.5 \mu \mathrm{g}$ dose, there did not appear to be any retinal or other intraocular-related toxicity. It may be that imatinib causes breakdown of the blood-retinal barrier even at low dosages. Therefore, intraocular use of this agent may be limited by drug toxicity.

The major limitation of this study is small sample size, that is, only 20 rabbits with intravitreal imatinib mesylate. Not only is the total number of rabbits injected in this study small, but as a result, the number of rabbits killed at each time point is also small (ie, only two rabbits injected at the $16.5 \mu \mathrm{g}$ dose of imatinib mesylate and one of which had possible evidence of toxicity). In addition, the determination of intraocular, specifically retinal, toxicity was based solely on histopathologic evidence. Future studies that included electroretinogram data would be helpful in confirming the lack of retinal toxicity in the absence of histologic changes with these targeted agents.

Imatinib mesylate at a dose of $1.65 \mathrm{mg}$ caused extensive retinal toxicity in rabbit eyes. In contrast, at lower doses, it did not appear to cause histologic signs of toxicity, except for one eye with apparent retinal oedema at the $16.5 \mu \mathrm{g}$ dose. Additional studies should be performed with larger sample sizes and include electroretinogram measurements to determine the safety of this type of intraocular therapeutic agent.

\section{Acknowledgements}

This was supported, in part, by an unrestricted grant from Research to Prevent Blindness Inc., NY, USA.

\section{References}

1 Fisburne BC, Wilson DJ, Rosenbaum JT, Neuwelt EA. Intravitreal methotrexate as an adjunctive treatment of intraocular lymphoma. Arch Ophthalmol 1997; 115: 1152-1156.

2 Arora A, Scholar EM. Role of tyrosine kinase inhibitors in cancer therapy. J Pharmacol Exp Ther 2005; 315: 971-979.

3 Litz J, Krystal GW. Imatinib inhibits c-Kit-induced hypoxia-inducible factor-1A activity and vascular endothelial growth factor expression in small cell lung cancer cells. Mol Cancer Ther 2006; 5: 1415-1422.

4 Fraunfelder FW, Solomon J, Druker BJ, Esmaeli B, Kuyl J. Ocular side-effects associated with imatinib mesylate (Gleevec). J Ocul Pharmacol Ther 2003; 19: 371-375.

5 Hurtado-Sarrio M, Duch-Samper A, Tobaoado-Esteve J, Martinez-Dominguez JA, Senent-Peris ML, Menezo-Rozalen JL. Anterior chamber infiltration in a patient with $\mathrm{Ph}+$ acute lymphoblastic leukemia in remission with imatinib. Am J Ophthalmol 2005; 139: 723-724. 